Nanuf act ur i ng pressuri zed creep tubes from hi ghl y purified $\mathrm{V} 4 \mathrm{Cr} 4 \mathrm{Ti}$ al I oys, N FS Heat 2

\begin{tabular}{|l|l|}
\hline 著者 & $\begin{array}{l}\text { FUKUMOTO } \mathrm{K}, \text { NATSUI H, NARUI M NAGASAKA T, } \\
\text { MUROGA T }\end{array}$ \\
\hline $\begin{array}{l}\text { j our nal or } \\
\text { publ i cat i on ti t l e }\end{array}$ & Jour nal of Nucl ear Nat er i al s \\
\hline vol ume & 335 \\
\hline number & 1 \\
\hline page r ange & 103 107 \\
\hline year & 2004 10 \\
\hline URL & ht t p: //hdl . handl e. net /10098/1159 \\
\hline
\end{tabular}




\title{
Manufacturing pressurized creep tubes from highly purified V-4Cr-4Ti alloys, NIFS-Heat2
}

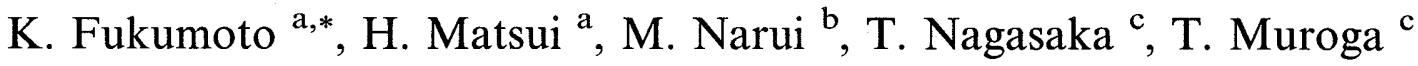 \\ a IMR/Tohoku University, 2-1-1 Katahira, Aoba-ku, Sendai 980-8577, Japan \\ b Oarai branch, IMR/Tohoku University, Oarai, Ibaraki 311-1313, Japan \\ c National Institute for Fusion Science, 322-6 Oroshi, Toki, Gifu 509-5292, Japan
}

\begin{abstract}
A fabrication process for pressurized creep tubes (PCTs) for a highly purified V-4Cr-4Ti alloy, NIFS-heat2 was established. No increase in impurity contents in PCTs was detected during the tube manufacturing process. In a preliminary thermal creep test, homogeneous deformation was observed over entire tube length, which verifies reliability of creep measurement by using the present PCTs.
\end{abstract}

\section{Introduction}

Creep deformation is one of the important issues that affect the lifetime of materials in a fusion reactor. At fusion relevant high temperature, creep strain rate of the materials at high temperature can be larger when excess point defects were generated by irradiation. In order to measure irradiation creep in pile of a reactor, several irradiation creep tests have been done using pressurized creep tubes (PCTs) [1-3]. Recently, high-purity $\mathrm{V}-4 \mathrm{Cr}-$ $4 \mathrm{Ti}$ ingots (NIFS-HEAT-1 and 2) were provided by National Institute for Fusion Science (NIFS), Japan [4-6]. The oxygen content of NIFS-HEAT-2 is almost half that of a large heat of $\mathrm{V}-4 \mathrm{Cr}-4 \mathrm{Ti}$ produced by a US-

\footnotetext{
* Corresponding author. Address: School of Nuclear Power and Energy Safety Engineering, University of Fukui 3-9-1, Bunkyo, Fukui 910-8507. Tel./fax: +81 776279712.

E-mail address: fukumoto@mech.fukui-u.ac.jp (K. Fukumoto).
}

DOE (Department of Energy) program [7]. In order to examine irradiation creep test for the highly purified $\mathrm{V}-4 \mathrm{Cr}-4 \mathrm{Ti}$ alloy, a manufacturing process of pressurized creep tube should be established at first with avoiding contamination of interstitial impurities during the process. We briefly report the manufacturing process of PCTs of highly purified $\mathrm{V}-4 \mathrm{Cr}-4 \mathrm{Ti}$, NIFS-Heat 2 that is planned to be used for high fluence neutron irradiation experiments in the future.

\section{Materials and manufacturing process of PCTs}

Fig. 1 shows a flow chart of manufacturing process for pressurized creep tubes of NIFS-heat2 alloys. Tube processing of NIFS-Heat2 alloys was successfully done by NIFS and Daido Co. The detailed tubing process has been reported in the Ref. [6]. The tubes were cut into pieces of pipes with one-inch $(25.4 \mathrm{~mm})$ length. Table 1 shows the contents of interstitial impurities in NIFS-Heat2 alloys used in this study. The results, 


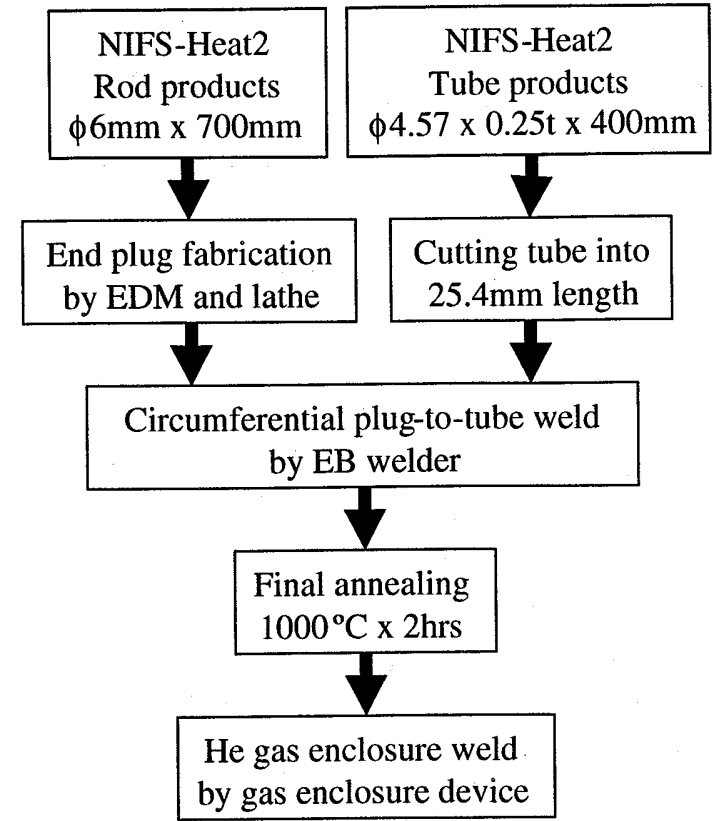

Fig. 1. Manufacturing process of a pressurized creep tube for NIFS-Heat 2 alloy.

Table 1

Interstitial impurity contents in the materials on the fabrication process (unit: wppm)

\begin{tabular}{lrrl}
\hline & $\mathrm{C}$ & $\mathrm{N}$ & $\mathrm{O}$ \\
\hline Ingot & 80 & 108 & 124 \\
As-rolled tube & 140 & 100 & 305 \\
Heat-treated tube & 120 & 120 & 330 \\
Final status of creep tube & 40 & 80 & 375 \\
\hline
\end{tabular}

shown in Table 1, indicate discernible uptake of oxygen during the tube fabrication. However the extent of oxygen content in the creep tubes is smaller than those in the previous creep tubes. The significant reduction of contamination of interstitial impurities during tube fabrication process was achieved by using the newly developed rolling process reported in Ref. [6] and the suitable intermediate annealing. Fig. 2 shows a blueprint of creep tube in this study. The design of the creep tube specimens was made in accordance with the previous work of creep tube specimens of vanadium alloys and ODSferritic steel [8]. A $8 \mathrm{~mm} \phi$ rod of the NIFS-heat2 alloy was cold-rolled to the $6 \mathrm{~mm} \phi$ rod. The end plugs were fabricated from a rod by using a lathe, and a $0.6 \mathrm{~mm} \phi /$ $0.25 \mathrm{~mm} \phi$ hole was bored in the top end plug with electro-discharge machining. The profile and dimension of the hole in the end plug was restricted by the request from helium gas enclosure technique. The circumferential plug-to-tube welds were made with an electron-beam



Fig. 2. A blue print of a pressurized creep tube for NIFS-Heat2 alloy.

(EB) welder in vacuum in a machine shop in Japan Atomic Energy Research Institute (JAERI), Tokai, Japan. A rotating revolver holder for six specimens was installed in the EB welder to reduce the frequency of opening the chamber of the EB welder. A condition of EB weld for PCTs of NIFS-Heat 2 alloys was as follows; $150 \mathrm{kV}$ for accelerating voltage of electron beams, $0.2 \mathrm{~mA}$ for beam current, two turn of $20 \mathrm{rpm}$ for rotation frequency of specimen holder and $<1 \times 10^{-2} \mathrm{~Pa}$ for the degree of vacuum. A quality inspection of defective welding and welding distortion was done for each PCTs after EB welding in JAERI by using radiography. The final heat treatment of PCTs was done at $1000^{\circ} \mathrm{C}$ for $2 \mathrm{~h}$ in vacuum of $<1 \times 10^{-4} \mathrm{~Pa}$. A helium gas sealing was done in a helium gas enclosure at the Oarai branch of Japan Nuclear Cycle Development Institute (JNC), Oarai, Japan. In this helium gas enclosure case, a plug pin was not used for enclosing. A top part of end plug was melted at a laser shot and solidified around 0.6 mm-hole-diam in the top end plug. The gas enclosure was done by the solidification of molten pool around an upper hole in the end plug. According to the request from gas enclosure system, the diameter of hole must be limited below $0.6 \mathrm{~mm}$ for upper part and below $0.3 \mathrm{~mm}$ for bottom part in the top end plug. In order to confirm that the laser weld does not make any pores or defects in the top end plug of NIFS-Heat 2 alloy, several designs of top end plugs have been used for demonstration tests. Finally, we determined the design of top end plug as shown in Fig. 2. The final closure welding of the 0.25mm-diam holes were made with a laser of $50 \mathrm{~J}$ power $(420 \mathrm{~V})$ through the quartz window at RT. The degree of vacuum was $<1 \mathrm{~Pa}$ after three times of helium gas exchanges. The high purity helium gas $(6 \mathrm{~N}$ grade, $<1$ wppm moisture and $<1$ wppm oxygen) was used. A maximum limit of inner pressure for inert gas enclosure is $29 \mathrm{MPa}$ in this device. As a result, a helium gas enclosure with $12 \mathrm{MPa}$ at RT was sufficiently achieved with the PCTs of NIFS-Heat alloy. For an example, a helium gas pressure of $11.2 \mathrm{MPa}$ at RT is required in a helium gas enclosure in order to obtain an effective applied 
stress of $200 \mathrm{MPa}$ in a PCT at $450^{\circ} \mathrm{C}$. Following a leak check, the dimensions of the assembled creep specimens were measured with a precision laser profilometer at five axial and 18 azimuthal locations to an accuracy of $1 \mu \mathrm{m}$. The details of creep strain measurement were referred to the previous works $[1,2,9]$.

\section{Quality inspection of fabrication process for PCT specimens}

Total numbers of finished creep tube specimens prepared for experiments were 52 so far. Eleven creep tube specimens were for thermal creep tests in liquid lithium environment, 14 specimens for thermal creep tests in vacuum, six specimens for thermal creep in liquid sodium environment, and 21 specimens for irradiation creep tests in the experimental fast reactor, JOYO. The final yield rate of successful creep tube fabrication, as defined by the ratio of the number of finished creep tubes to the total numbers of creep tubes, was about $80 \%, 52$ successful cases out of 65 trials. However, most of failures were detected at the process of EB welding in early days. It is anticipated that the yield rate will be improved with experiencing manufacturing many times.

A macroscopic examination of the welds indicated relatively smooth weld zones without any cracks, porosity, or other significant weld flaws. Weld cross-sections of the specimens with inner charged pressure of 12 $\mathrm{MPa}$ at room temperature were examined by confocal laser microscope. In addition, Vickers microhardness measurements with loads of 25 and $200 \mathrm{~g}$ were made at the weld zone in the plug-to-tube welds and the helium gas closure welds of top-end plug. The load of 25 $\mathrm{g}$ in Vickers microhardness was employed in order to investigate a hardness profile in a selected area and the load of $200 \mathrm{~g}$ was employed in order to measure the accurate hardness value. Fig. 3(a) shows an optical photomicrograph of the cross section of plug-to-tube weld made by the EB welder. Specimens were chemically etched in a solution of $10 \% \mathrm{HF}-40 \% \mathrm{HNO}_{3}-50 \%$ water for metallographic examination. The grains in the weld zone were of the order of 3-8 times larger than those of the base metal away from the weld. The center of weld zones did not contain any fine structures of precipitates in a grain, but the weld cross-section shows the definite contours around the root region of welded zone, along which preferential segregation of impurities can occur. Fig. 3(b) shows a Vickers microhardness distribution of weld zones made with EB welder. The mean hardness of tube and plug were $160 \pm 2$ and $160 \pm 3$, respectively. The hardness profiles indicated a small drop in the weld centerline region from 160 to 150 . The significant increase of hardness due to the preferential segregation of impurities could not be seen in the root of weld zone. From these results, it is deduced that
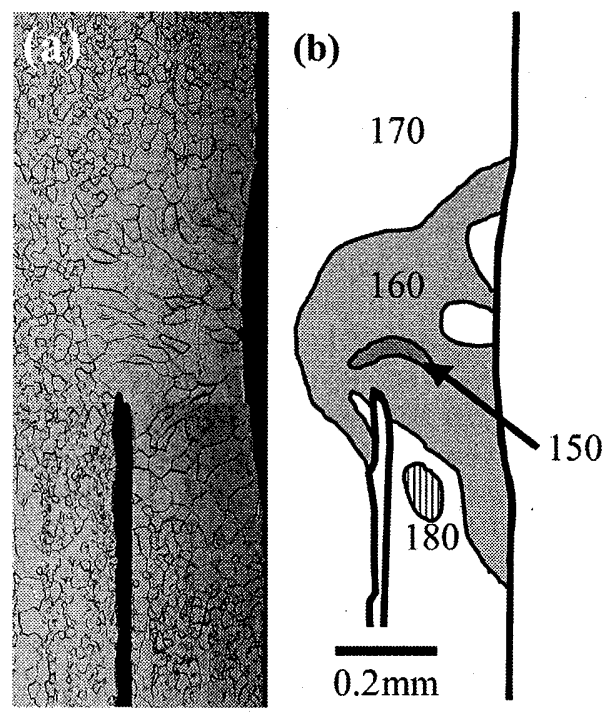

Fig. 3. An optical micrograph and a hardness contour map of the cross section of plug-to-tube weld.

the contamination by interstitial impurities during the EB weld did not occur in the circumferential plug-totube welds.

Fig. 4(a) shows an optical photomicrograph of the cross-section of helium gas closure weld made with the laser welder. The grains near the top of the weld zone in the end plug were columnar, which is dictated by heat flow and solidification. Even in the root of the weld, the grains were of the order of 2-8 times larger than those of the base metal. In addition, the fine structures in the grain indicating the precipitates were observed in the fusion zone. Fig. 4(b) shows a hardness distribution of weld zones made with gas enclosure welder on the top end plug. The hardness on heat-affected zone near outside surface did not change significantly from the base metal. In Fig. 4(b), gray zones indicate the areas where
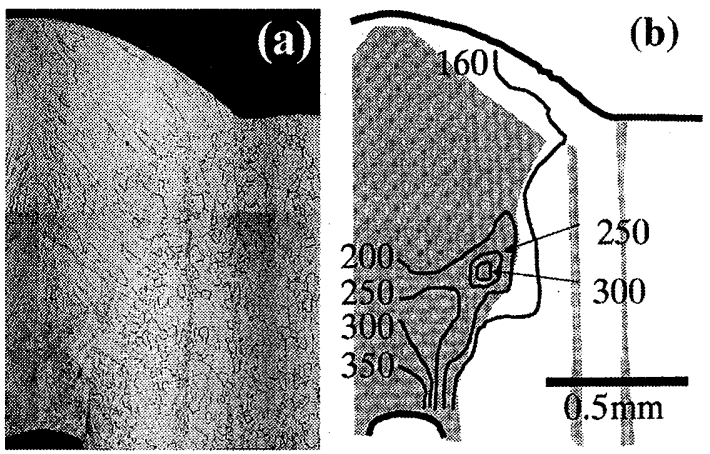

Fig. 4. An optical micrograph and a hardness contour map of the cross section of helium gas closure weld. 
fine structures in the welded zone and precipitate bands in the tube part can be seen. There were no fine structures in grains of heat-affected zone near the outside free surface. Around the center of welded zone near the top surface, the hardness increased up to 180 and fine structures in columnar grains were observed. The hardness increased along the line from the top surface to the root of welded zones in the end plug. Though not shown in Fig. 4(b), the hardness profile shows a peak value of 410 at the bottom of weld zone in the end plug. Nagasaka has reported that the change in the hardness due to gas tungsten arc (GTA) welds depended on the oxygen level of the base metals, and the precipitation hardening due to post weld heat treatment increased with increasing the oxygen level [10]. The fine structures in grains in the welded zones in this study appear to be $\mathrm{Ti}(\mathrm{O}, \mathrm{N}, \mathrm{C})$ precipitates, though the microstructural analysis of them has not been done. It is considered that increases of the densities of precipitates cause the significant increases of hardness in the welded zones. Especially, it is considered that contaminant oxygen and other interstitial impurities entered into welded pool at the root of the top end plug from helium gas during the gas enclosure welds, since the significant changes of hardness up to 400 were observed. However, the hardening is not expected to have deleterious effect on the performance on creep tests, because the solid solute hardening due to interstitial impurities will increase the creep strength.

\section{Preliminary creep examinations}

Preliminary creep tests for checking the deformation behavior of PCTs were done. Fig. 5 shows examples of PCTs after creep test at $850^{\circ} \mathrm{C}$ and a sample with 4.57 $\mathrm{mm} \phi$ of outer diameter for comparison. The specimens showed the uniform dilatation at the tube part and values of effective creep strain of specimens were estimated

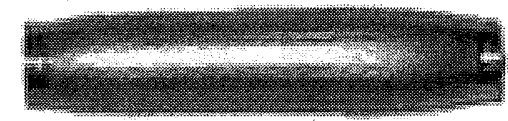

$850^{\circ} \mathrm{C}, 200 \mathrm{MPa}, 50 \mathrm{hr}$

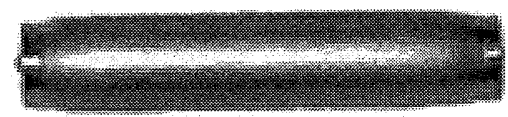

$850^{\circ} \mathrm{C}, 150 \mathrm{MPa}, 118 \mathrm{hr}$

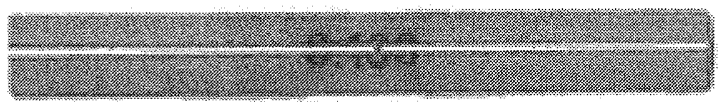

A sample with $4.57 \mathrm{~mm} \phi$ Dia.

Fig. 5. Examples of PCTs after creep test. A standard rod of $4.57 \mathrm{~mm}$ in diameter was shown as well as creep samples. to be $20 \%$ for the specimens. It is suggested that there is no fabrication defect in the tube leading to unexpected rupture during the creep test, and it is possible to measure the effective creep strain up to $20 \%$. Further thermal creep tests for NIFS-Heat2 from 600 to $800^{\circ} \mathrm{C}$ by using these PCTs are in progress. Consequently, the procedure for the PCT fabrication of highly purified $\mathrm{V}-4 \mathrm{Cr}-4 \mathrm{Ti}$ alloys has been established.

\section{Conclusion}

Thin-wall tubing was produced from the NIFS-Heats of highly purified $\mathrm{V}-4 \mathrm{Cr}-4 \mathrm{Ti}$ to study the thermal and irradiation creep behavior. In order to fabricate PCTs for NIFS-Heat alloys, a fabrication process for PCTs was established with taking care of avoiding contamination of interstitial impurities during fabrication process. In the EB weld, there was no defective weld and significant hardening in the welded zone. In the helium gas enclosure, no defective weld like pore could be seen. No increase in impurity contents in PCTs was detected during the tube manufacturing process. In a preliminary thermal creep test at $850^{\circ} \mathrm{C}$, homogeneous deformation was observed over entire tube length up to $20 \%$ of effective creep strain after creep test. It is suggested that there is no fabrication defect in the tube part to make unexpected rupture during the creep test and the procedure for the PCT fabrication of highly purified $\mathrm{V}-4 \mathrm{Cr}-4 \mathrm{Ti}$ alloys has been established here.

\section{Acknowledgments}

This work has been performed in collaboration with the NIFS, JAERI-Tokai and JNC-Oarai. Especially, the authors wish to thank S. Onose, Y. Abe and S. Ichikawa of JNC-Oarai and T. Kikuchi and F. Isozaki of JAERI-Tokai for their technical skill for creep tube fabrication.

\section{References}

[1] H. Tsai, H. Matsui, M.C. Billone, R.V. Strain, D.L. Smith, J. Nucl. Mater. 258-263 (1998) 1471.

[2] K. Fukumoto, H. Matsui, H. Tsai, D.L. Smith, J. Nucl. Mater. 283-287 (2000) 492.

[3] J.M. Vitek, D.N. Brrraski, J.A. Horak, J. Nucl. Mater. 141-143 (1986) 982.

[4] T. Muroga, T. Nagasaka, A. Iiyoshi, A. Kawabata, S. Sakurai, M. Sakata, J. Nucl. Mater. 283-287 (2000) 711.

[5] T. Muroga, T. Nagasaka, K. Abe, V.M. Chernov, H. Matsui, D.L. Smith, Z.-Y. Xu, S.J. Zinkle, J. Nucl. Mater. 307-311 (2002) 547.

[6] T. Nagasaka, T. Muroga, T. Iikubo, Fusion Sci. Tech. 44 (2003) 465. 
[7] H.M. Chung, B.A. Loomis, D.L. Smith, J. Nucl. Mater. 239 (1996) 139.

[8] S. Ukai, M. Harada, H. Okada, M. Inoue, S. Nomura, S. Shikakura, T. Nishida, M. Fujiwara, K. Asobe, J. Nucl. Mater. 204 (1993) 74.
[9] R.J. Kurtz, M.L. Hamilton, J. Nucl. Mater. 283-287 (2000) 628.

[10] T. Nagasaka, T. Muroga, M.L. Grossbeck, T. Yamamoto, J. Nucl. Mater. 307-311 (2002) 1595. 